\title{
'SKILLS TO PAY THE BILLS': \\ GENDER DIFFERENCE IN MOUNTAIN BIKING ON DISPLAY
}

\author{
Mike Lloyd ${ }^{1}$
}

\begin{abstract}
This paper analyses a short video showing the opening of a skills area in a mountain bike park. After the official ribbon cutting by the mayor, we watch nearly twenty mountain bikers putting in some showy runs. Amongst this, there are only three women riders, and in contrast to a core group of young male riders, they appear to ride very cautiously. Given this contrast, a possible reaction to the video is that it is 'sexist', giving the message that women are less competent at mountain biking, bolstering an existing view that 'mountain biking is for men'. Clearly, a single video needs to be treated with caution, nonetheless, the gender difference is stark. However, by considering the specifics of mountain biking skills, and its 'interactional ecology' the interpretive point made from the video is that the assumption of gender difference may need 'undoing'. This is pursued not by conceptual discussion, but by showing what can be made of the video in analysing key visual fragments. Additionally, the details of the video are supplemented by reference to one other key piece of cycling research, and one other 'natural video record' of mountain biking practice. The paper contributes to the growing recognition of the value of video data in the ethnographic analysis of mobile interactive practices.
\end{abstract}

Keywords: mountain biking; display; gender; video

\section{INTRODUCTION}

New Zealand is fast becoming something of a mountain biking paradise. There are several world class mountain bike parks - Rotorua, Wellington, Christchurch, Queenstown - full of exciting tracks, and quite apart from these sculpted downhill runs where a fee is often paid for entrance, the local topography provides ample hills, mountains, and even river valleys, that provide excellent free mountain biking. The essential guide to mountain bike tracks in New Zealand 
(Kennett, Kennett, and Kennett 2014) is so popular it is in its ninth edition, being updated regularly to incorporate the new tracks built every year. As with all idylls, however, there is possibly some trouble in paradise. It stems from the distinct possibility of a gender imbalance, something indicated in the title of a recent academic analysis of videos and magazines surrounding the sport: 'mountain biking is for men' (Huyber-Withers and Livingston 2010). Related, though also referencing road cycling, is the well-known acronym MAMIL middle-aged men in lycra - which does not appear to have a female equivalent, suggesting again that mountain biking is predominantly for men. Taking this gender difference at face value, and given there are no good reasons why women cannot enjoy the pleasures of mountain biking, there is a sociological topic worthy of investigation: what are the specifics of the gender imbalance, and why is mountain biking dominated by males?

It is not possible to fully answer the second more general question in the space of a single journal article, but here I do contribute to the more specific investigation of the gender imbalance in mountain biking, even if the final form of this contribution is to say that we should not jump to conclusions about the nature and spread of such imbalance. This point is made by a single case analysis of a short mountain biking video, which seems to show an obvious gender difference in riding style. In brief, the video shows the opening of a skills area in a well-known mountain bike park, but only three of the nineteen riders shown riding in the opened skills area are women. Moreover, at first glance, in contrast to the showy riding of a group of young males, the women appear to ride very cautiously. The first step below is to overview the video, but then via a number of conceptual contributions move the discussion to the topic of skill itself. In doing so, our attention is drawn to the ways in which a deceptively simple video is undergirded by a notion of audience reception, where the properly intended audience enacts a kind of 'professional vision' (Goodwin, 1994) in their viewing of the video. It is this, ultimately, that might lead to the view that we are not necessarily viewing a video intended to bolster a 'mountain biking is for men' reading.

\section{MAKARA PEAK MOUNTAIN BIKE PARK AND THE SKILLS AREA VIDEO}

Located only twenty minutes from downtown Wellington, Makara Peak Mountain Bike Park opened in 1998. It covers 250 hectares of public land, with 412 metre high Makara Peak at its centre. The nearly fifty kilometres of tracks were built, and are maintained by volunteers, with city council approval and assistance. Ten years after the opening, the Skills Area was added to the resource 
that the park offers. Skills areas, along with 'pump tracks', are a common feature of mountain bike parks worldwide, and they typically reproduce elements of track features found in the surrounding park. Whereas formal instruction by skilled mountain bikers can occur in the skills area, as when parents teach their children how to ride, this is quite infrequent. Instead, more commonly, it is entirely up to riders what use they make of the features in the skills area, and indeed whether that use is for the purpose of practicing skills (it could, for example, just be used to have a lunch break from the main ride).

It is useful to begin with a quick description and introductory comment on the short video ${ }^{2}$ that is the key focus below. It begins with a 'Skills Area' sign, superimposed with 'Makara Peak Grand Opening 22 April 2007.3 Aretha Franklin's song 'Respect' starts and the action moves to a crowd gathered below a woman, dressed in lycra and wearing a cycle helmet, standing on a platform. This is the Mayor of Wellington, who cuts a ribbon saying, 'it gives me great pleasure in declaring this new skills area officially open, and thank you', the only spoken words in the 4.04 minute video. We see and hear the crowd applauding, then the camera moves to follow a man and young girl, riding on the man's bike which has attached to it a single-wheel 'ride along bike' where the young girl sits. They had previously been assisting the mayor on the platform, but now, through their actions, the platform is transformed into its skills area mode: it is a ramp that offers three levels for riders to drop off. In response to the pair's successful negotiation of the lowest level drop, there is much whooping and applause from the crowd. 'Respect' still plays throughout this action with its relevance being obvious, that is, the volunteers who built the skills area deserve respect.

At 49 seconds into the video, as the father and daughter slowly crest a hump, the $R \& B$ of Aretha Franklin's 'Respect' gives way to a rap song. It is the Beastie Boys' 'Skills to pay the bills', and in-sync with its strident beat and lyrics, the mountain biking action changes. Just above the ramp where most of the action has previously occurred, we briefly see three young male riders sitting on their bikes. One of these descends towards the ramp, this time riding off the highest level at speed, dropping more than a metre and then 'getting air' over the same hump which the father and daughter had cautiously crested. Thereafter, with the rap song and chorus 'I've got the skills to pay the bills' continuing, we watch nineteen mountain bikers riding the skills area in varied ways. By the end of the video there have been thirty-two runs, only three of which feature women. Moreover, in contrast to many of the male riders who seem keen to display just how aggressively they can ride, the three women appear to ride very cautiously. 


\section{A natural reaction to the gender difference?}

I have shared the video with groups of sociology students and colleagues, and on a first viewing it is this gender difference that claims most people's attention. Some additional information helps to elaborate this claim. About the time I started working on this video, I came across an article in a mountain biking magazine about a recently retired female downhill mountain biker - Scarlett Hagen - who had just set up a business teaching mountain bike skills. Because the article also mentioned that she had just completed a thesis on mountain biking, I emailed Hagen saying I was working on this video and shared a link to it. Hagen's emailed response was brief:

It is interesting to reflect on the development that has occurred from when this video was filmed in 2007. In many ways mountain biking has changed dramatically since then - especially with the inclusion of female only events, women's coaching days and women specific riding groups. However, with this said, it is still a male dominated sport - nonetheless there have been interesting progressions (such as equal prize money, and inclusion of women into Crankworx [an international-brand event, run in Rotorua] which have helped gender equality in recent years. (personal communication, December 11 2015)

Hagen suggests that eight years after the filming of the opening of the skills area, things have changed. It may be that with the type of skills training that Hagen herself now offers, there are far more women mountain biking, and many of them may be riding in a manner similar to men. This may all be true, but what is most interesting about Hagen's comments is that they stem from the base assumption that in the runs shown in the video the gender disparity is there for all to see. That is, it is so obvious that it does not need detailing, rather she simply proceeds to suggest that things have now changed; the view of mountain biking seen in the video is now outdated as there is now a more 'gender equal' situation.

Obviously, Hagen's comments are an informal response, however, it might be seen that they contain the seeds of a relatively traditional avenue of research. Even though there is not much research specifically on mountain biking, from what there is the point has already been made that 'mountain biking is for men' (the title of Huybers-Withers and Livingston's [2010] analysis of videos and magazines surrounding the sport). This specific claim could be connected to a literature on 'alternative' sporting practices with a family resemblance to mountain biking, arguing that male dominance in such sports is common 
(see Rinehart and Sydnor 2003). What is apparent in this literature is a common assumption that in these practices women do the equivalent of 'throwing like a girl' (Young 1990), that is, in many physical activities girls and women restrict their movements, confining them and limiting their engagement with the world, ultimately making them appear less able than males (for examples of how the term 'throwing like a girl' is applied see Jutel 2009; Kotarba and Held 2006). Whereas this claim deserves further research, it is not pursued here as I want to approach the video anew, asking: 'how can we look into the mountain biking video in greater depth?' Answering this entails a strong descriptive emphasis, building up finely detailed observations around the questions of what we take to be a skill, exactly where and how we recognise competence in mountain biking, and how this is all socially organised around interactional ecologies' (Nevile et al. 2014). If we take such questions to be important, then an apparently unremarkable video becomes an exceptional resource for a finegrained analysis of mountain biking skill on display. Taking into account space constraints, the aim below is to provide as much visual detail as possible.

\section{FRAMING THE VIDEO AND THE SITE}

The first point to note is that the video is not a 'one-time through' naturally occurring record of what happened in opening the skills area. I was not at the opening, but it seems reasonable to believe it lasted at least thirty minutes, so, at just over four minutes, the video is obviously an edited and framed record of what happened, which also in its final presented form includes three music tracks. Something that is also important to consider, though difficult to answer, is the question of who the intended audience is and who actually watches it? There is the obvious 'reasonable' answer that it is for both, people with a general interest in mountain biking, and specifically, those who go mountain biking in the Makara Peak Park (there is a supporters group). That accepted, it can also be argued that the video is designed to be sensible to almost any viewer. Whereas it is selective, in its four minute length it does many things that we would 'naturally' expect to see, that is, there is nothing mysterious about the way the filmed activities are packaged together to accomplish an 'opening. Someone with authority and status ritually performs an 'opening, usually by saying a few words, and then the activity that is afforded in the area now opened is engaged in. So, a tennis club opens a new court, then tennis is played; a new walkway is opened, then people walk it; and, in our case, the mountain biking skills area is opened, and then people ride it. It is important to emphasise that in our case, the interesting question is how that riding might be observably-and-reportably 'skilled' riding. This is to open up our inquiry into the riding as a 'normatively organised course of doings' (Sudnow 1993, 
153), which has a surprising parallel with Sudnow's study of learning to play jazz piano. As Sudnow notes, whereas he began his jazz lessons with prior competence on the piano, he then discovered that 'doing jazz improvisation correctly, however, was another matter' (1993, 2). Similarly, having competence in riding a standard bicycle on paved flat ground, does not mean a cyclist can easily transition to skilled riding on mountain bike tracks (and that is why there are skills areas).

The specifics of mountain biking skills can be opened up by careful consideration of data, such as we have to hand here in the video, however, first it is useful to consider a visual overview of the skills area, shown in Figure 1.

Figure 1 collates three photographs taken in May 2016, in order to give the reader a feel for the physical terrain of the skills area. It shows that the area is a reasonable size, offering several features for people to ride. Not all features are shown in the photos, but we can clearly see two jumps, and the three levelramp. The white sign at the edge of the area is a mapboard showing the tracks in the broader park, two of which actually feed into and out of the skills area. The table is the area around which, on the day of the opening, the bulk of the crowd were gathered to watch the opening and the subsequent riding. Importantly, we can see from all three photos that the slope from above the ramp the staging area - is quite steep, allowing a rider to generate considerable pace, before choosing which downward route they take: off one of the levels of the three-level ramp; riding onto Jump 1 or 2, or avoiding these jumps to move onto another feature of the skills area. It can also be seen that the ground and jumps are not carefully manicured, instead the area is relatively well-worn with native vegetation subsisting around the ridden areas.

Additionally, it is important to note something that is not there: there is no signboard giving an instructional guide as to how to use the features of the area to develop mountain biking skills. This lack of explicit instruction does not mean that the terrain of the skills area is blank, lacking any guidance on what is to be done within. Currently, within the social sciences, 'sociomateriality is "the New Black"' (Jarzawbkowski and Pinch 2013), and within the material turn academics have been emphasising that material objects 'do things'; hence 'objects' are now a key candidate for where the guidance in the skills area is to be found. Whether it is via the term 'program', 'actant' or 'script' (Akrich 1992; Latour 1992), or back to the earlier notion of 'affordance' (see Dant 2014), it is emphasised that objects are not just 'placeholders', merely transporting action from elsewhere. Rather, objects demand a certain set of competencies by the actors they line up, they in turn are both changed by their circulation and 

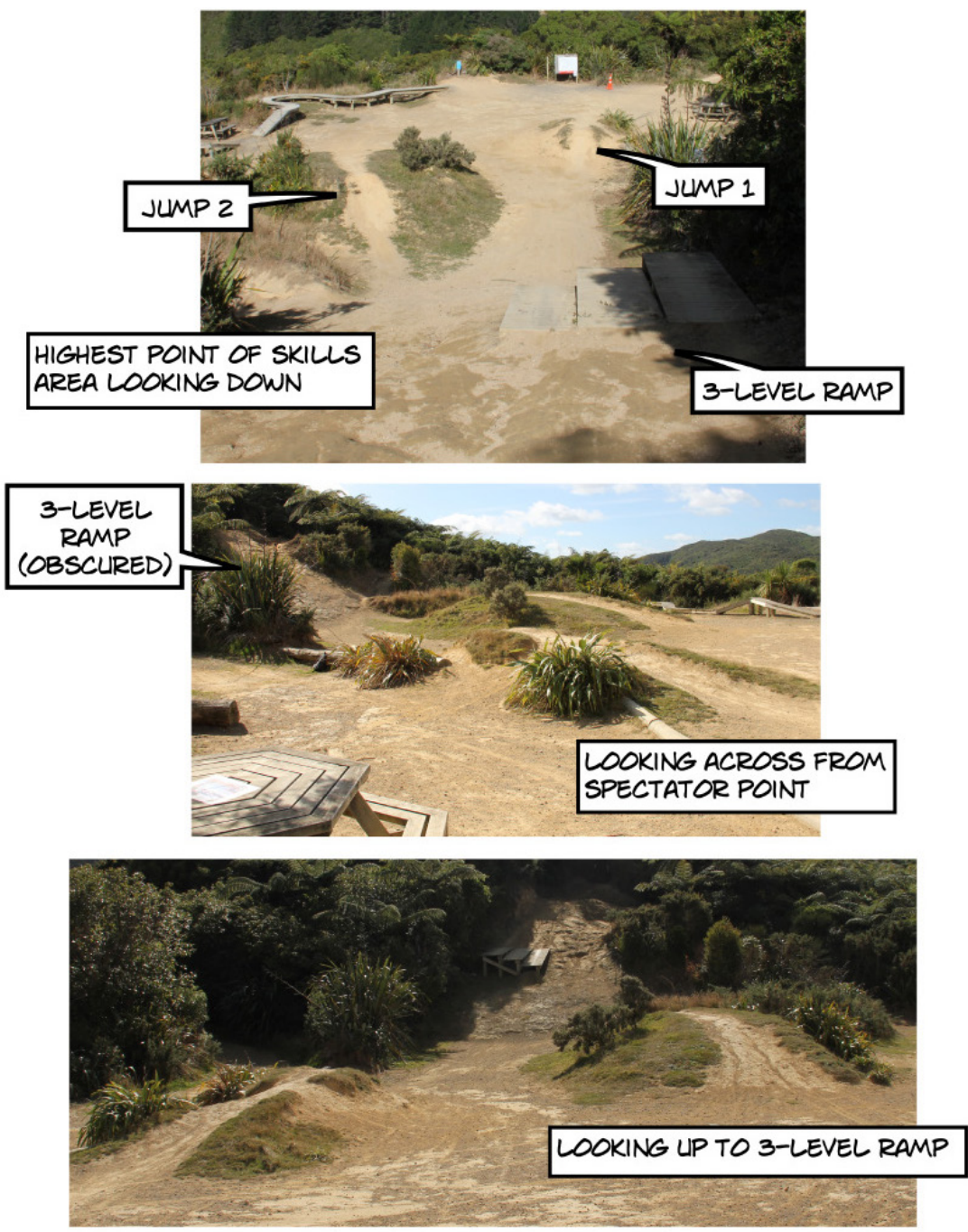

Figure 1. Layout of the skills area showing key features.

change the collective through their circulation (Sayes 2014). This emphasis on sociomateriality and objects doing things looks very attractive even given a cursory glance at Figure 1: the three-level ramp, the jumps, and their connectedness via a steep slope - all seem to be capable of acting upon the mountain bikers that find themselves in the area (and, in Latour's [1994] well-known discussion of 'speed bumps' there is discussion of an object not dissimilar in 
kind to the humps of dirt we see in Figure 1).

However, in relation to the sociomaterial turn, I find it useful to eschew discussion of 'actants' and instead carefully recover from ethnomethodology some guidelines for understanding the practices we see being carried out in the skills area. A well-known early piece from Garfinkel and Wieder is particularly useful, stating that:

To find a perspicuous setting the EM policy provides that the analyst looks to find, as of the haecceities of some local gang's work affairs, the organizational thing that they are up against and that they can be brought to teach the analyst what he needs to learn and to know from them.... (1992, 186, original emphasis)

Simply, I take the skills area and the record of the riding at its opening to be a 'perspicuous setting', with its own 'organizational thing' that needs to be detailed. In a footnote, Garfinkel and Weider elaborate 'organizational thing' as follows, with appropriate extensions added in hard brackets:

That although it is of their doing, and as of the flow they are "witnessably oriented by" and "seeably directed to" the production of it, they treat the organizational thing as of their doing, as of their own doing, but not of their very own, singular, distinctive authorship. And, further for just this cohort [the group of riders] it will be that after they exit the freeway [skills area] others will come after them to do again the same, familiar things that they - just they - just these of us as drivings [ridings] doings are in concert doing. (Garfinkel and Wieder 1992, 204, fn 3, original emphasis)

To put it another way, in the lived details of the riding seen to open the skills area, the riders, to adapt a phrase from Maynard, 'put the flesh on the skeleton' $(2012,218)$. Here I take the skeleton to be both the physical materials of the skills area, and the distant work of its builders who have built it in line with their preconceptions of what sensible, coherent, familiar, do-able and competent mountain biking practices are. Consequently, in looking at the video of the skills area opening we are looking at the record of an organisational thing, even if it is edited and framed after-the-event. Moreover, whereas the sociomaterial turn might encourage us to dig deeper into the power of the actants or objects, here I return to the basic ethnomethodological question of just how and with what variation the riders use the material of the site to constitute skilled mountain biking as an observable-reportable phenomenon. 
In the short description above, it was noted that the first 'run' in the video was by a father-daughter pair who were standing alongside the mayor and had assisted her in cutting a ribbon. After their ride on a type of tandem bike that is not usually ridden on mountain bike tracks, the gathered crowd cheers and claps - the only time this occurs in the video. Consequently, this first riding can be seen as a transition from the activities of the opening as a ritual, into what might typically be seen as skilled riding. As noted above, the transition between the two is marked by a change in music: from 'Respect', to 'Skills to pay the bills'. Right throughout the video, it is careful choices like these that build the picture of mountain biking skills. By assigning an alphabetic label ${ }^{4}$ to each rider we can show the number of rides for each and the overall sequence of appearance:

$$
\begin{aligned}
& \text { A/B-C-D-E-F-G-H } \backslash D-H \backslash D-I-H-D-I-J-K-I-L-H-C-M-K-H-N-O-P-Q- \\
& \text { R-L-S-D-K-H-K }
\end{aligned}
$$

This gives the total number of runs as thirty-two, where A/B is the tandem run by the father-daughter pair, and $H \backslash D$ is a duo run, that is, where two riders ride the same path with a small gap between them (both the father-daughter and duo runs are counted as singular runs). An interesting thing that the sequence shows is that six of the full complement of nineteen riders do more than one run, with these six (C, D, H, I, K, L) doing twenty-one of the thirty-two runs. This constitutes two-thirds (65.6\%) of the riding action we see. None of the three women riders are amongst this group of repeat-riders, moreover, the combined time that we see the women riding is fourteen seconds, that is, $8.4 \%$ of the 2:47 minutes of the video that shows riding.

This first description seems important for building our understanding of the organisational thing under analysis, and we can pursue this by asking two questions. First, what kind of riding do we see the six repeat-riders display, and second, how does the riding of the three women compare to the pattern set up by the 'dominant' riders? Answers to both of these questions are pursued below using figures employing screensnaps from the video. Clearly, given that there are thirty-two runs in total, there has to be some selection from the full number of runs, and also in the number of screensnaps chosen to show the details of a particular run. Additionally, in the following figures, there is a focus on runs from above the three-level ramp ${ }^{5}$ - the staging area - down onto either Jump 1 or 2 , thus excluding other features of the skills area. These excluded features are important, but space constraints preclude full coverage; 
the selection that is shown is sufficient to serve the analytic aim of seeing the variety in the skilled riding and allowing comparison across the riders. In all of the figures, the letter in the label refers to the position in the full sequential chain noted above, and the number refers to the run number.
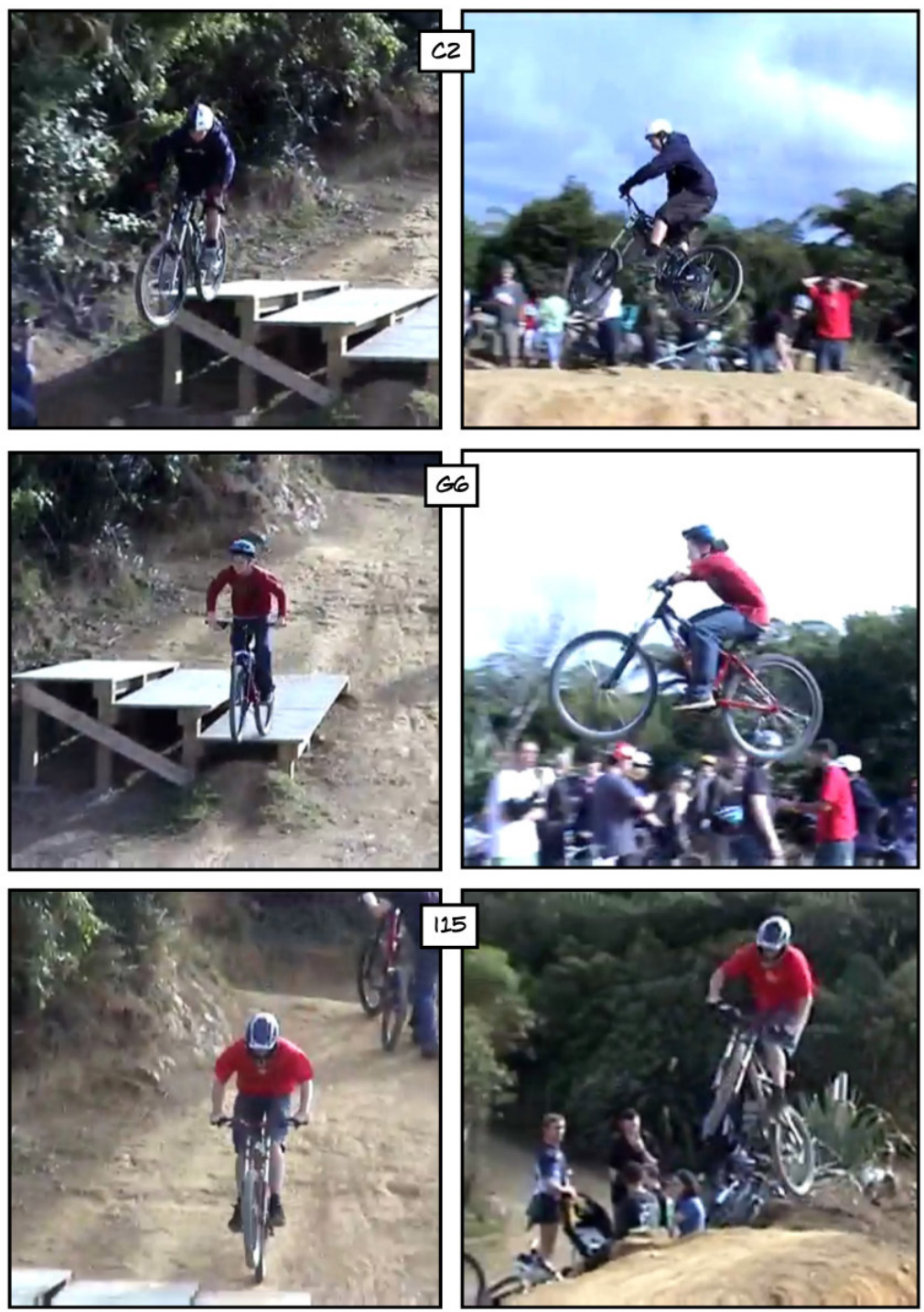

Figure 2 

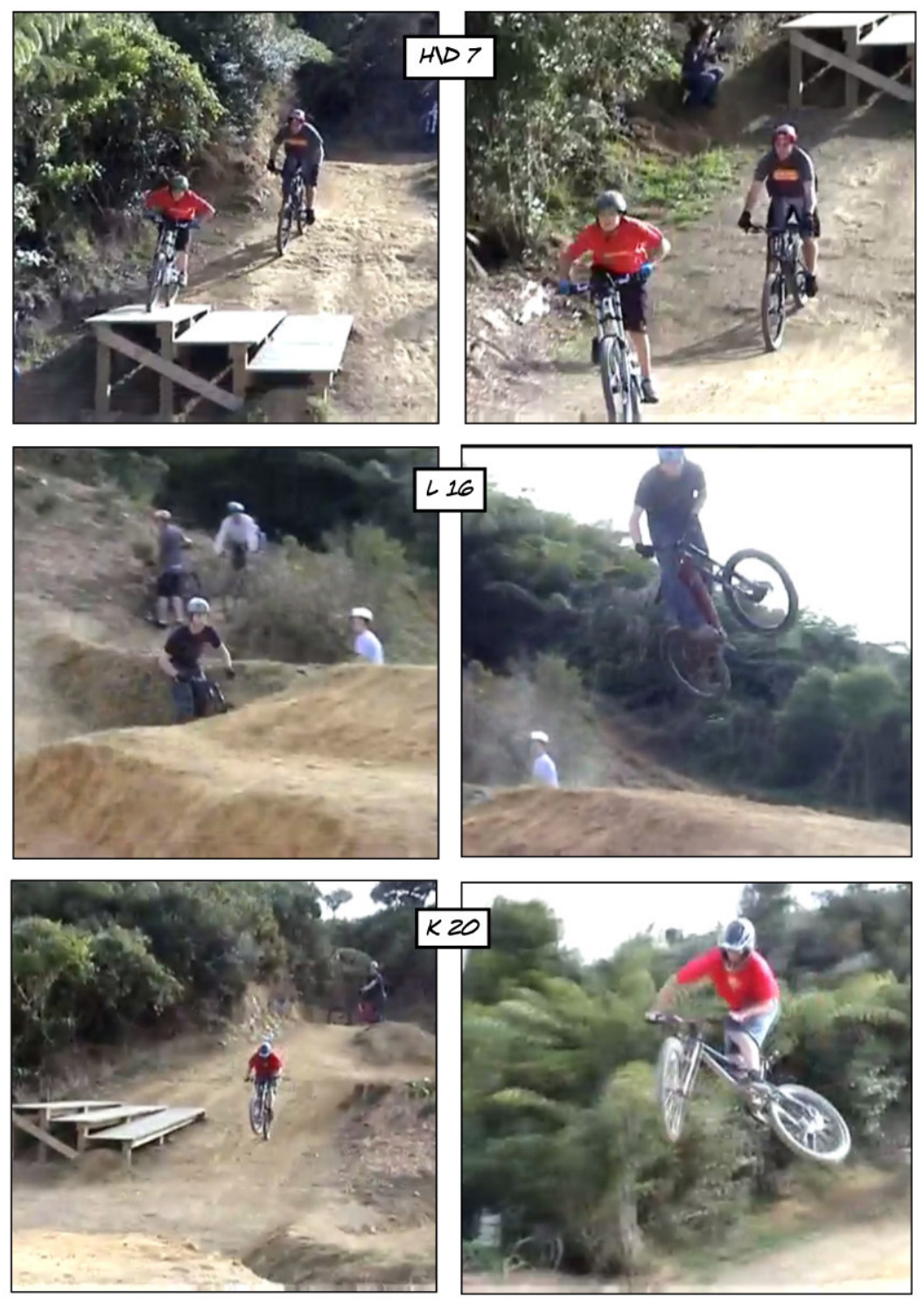

Figure 3

In Figures 2 and 3, all riders except G6 are one of the group of repeat-riders. They are all male, and from appearances it is fair to say they are all young: G6 seems the youngest, perhaps being twelve or thirteen, with the others being 
in the mid-teens to early twenties. None wear the lycra typical of road cyclists and some competitive mountain bikers, rather they are in streetwear, albeit with gloves and helmets. Looking at the runs themselves, captured via only two screensnaps each, in Figure 2 we see: $\mathrm{C} 2$ riding off the highest level of the ramp, gettting air on Jump 1; G6 off the lowest level, nonetheless getting very high in the air on Jump 1; I15 manualling - lifting his front wheel off the ground before going off the lowest level and getting air with a 'whip' on Jump $1 .{ }^{6}$

In Figure 3 we see even more variety to this skill on display. First, we see in $\mathrm{H} \backslash$ $\mathrm{D} 7 \mathrm{an}$ example of 'duo' riding: with only a few metres between them, $\mathrm{H}$ rides first off the highest level, D follows, and not shown, they continue onto Jump 1 with both getting air off the jump, all the while maintaining the close distance between them. Second, we see L16 coming down from the staging area, getting big air on Jump 2 and whipping his back wheel while in the air. Similarly, K2O shows the rider whipping on Jump 2, but he is also seen to manual while riding down from the staging area. Bear in mind that this is all seen whilst 'Skills to pay the billls' plays. In total, the riding seen in Figures 1 and 2 comprises thirtythree seconds of the full 2:47 minutes riding seen in the video. So, the average view of each run is about six seconds, and this is consistent with the full video as it is effectively a compilation of many mountain bikers glimpsed riding for a few seconds each. As noted, there is further variety to the riding not shown in these two figures - including a unicyclist and a preschooler - nonetheless, the figures well capture the dominant view from the video: young male riders, displaying great confidence in the full range of their mountain biking ability. In short, they have the mountain biking skills to pay the bills.

Amidst this dominant pattern, at 2:30 minutes into the video the first female rider completes a run, and shortly thereafter two others follow. All three are shown in Figure 4.

At the outset we can see that the women are not as young as the males previously seen: $\mathrm{N}_{22}$ is possibly in her late twenties, and the others are probably the oldest riders seen riding at the opening of the skills area. Secondly, we see that all three go off the lowest level of the ramp, with Q25 and R26 riding onto Jump 1, whereas N22 bypasses the jumps going between Jumps 1 and 2. Neither of Q25 and R26 in their riding up and through Jump 1 get airborne in the process, and both remain seated on their bike's saddle throughout their run. N22, in contrast, can be seen to rise off her saddle when going off the ramp, and she also rides at a faster pace than the other two women.

As noted, the three women's run occur quite late in the piece, after the riding 

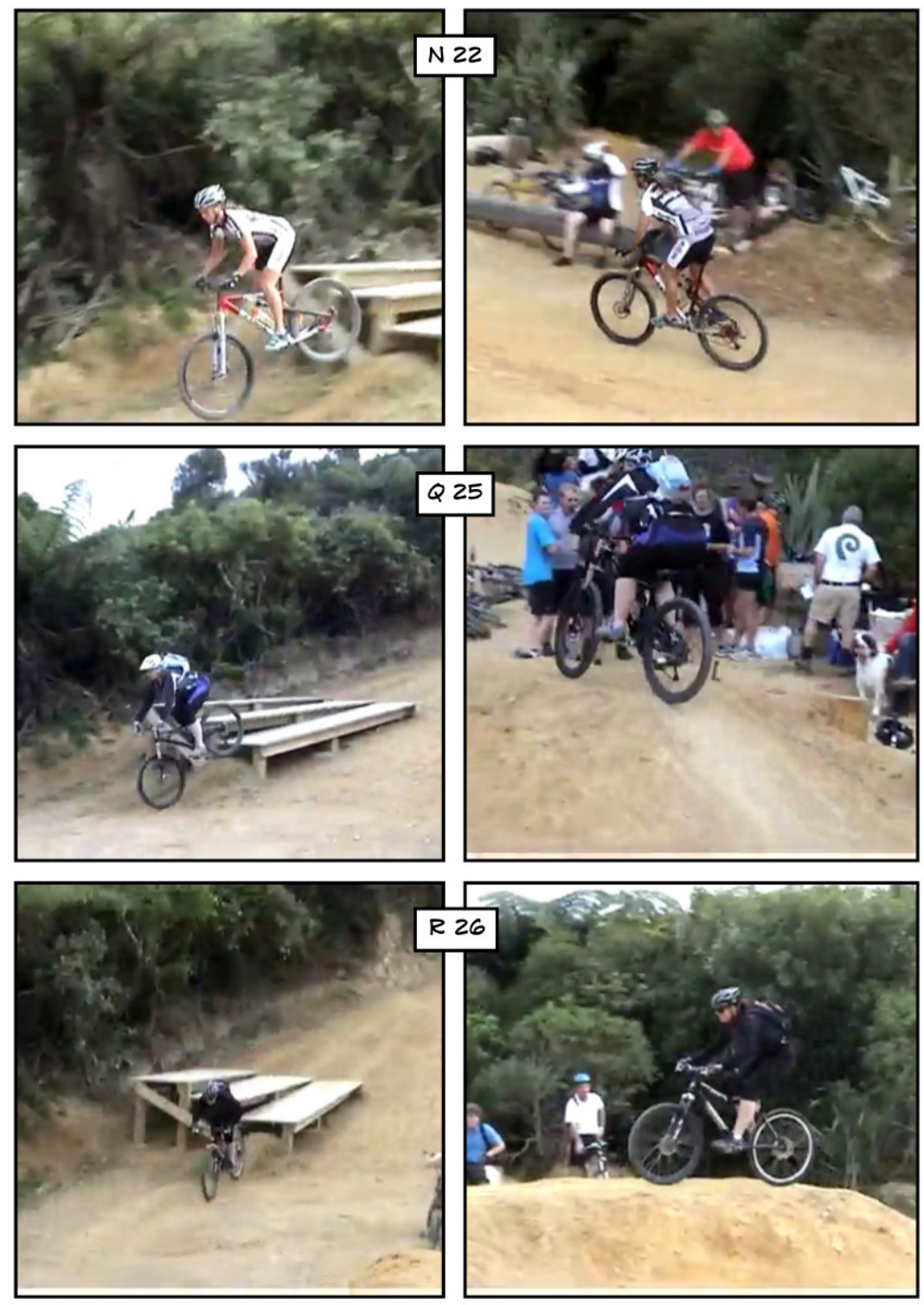

Figure 4

of the 'dominant' young males, who we have seen above. Collectively, these noticeable features are one reason for why, as noted above, many sociologist- 
viewers take the most interesting sociological issue in the video to be that of gender difference. Further, for those with some mountain biking experience, the details of the riding can be seen to reinforce the interest in gender difference. In this respect a comparison of the first frames of Q25's and G6's (Figure 2) runs are instructive. Both show the two riders going off the lowest level of the three-level ramp, but there is quite a significant difference in how they do this: Q25 goes off slowly, with her front wheel dropping and landing first, whereas G6 goes much faster and can be seen lifting his front wheel just as he leaves the ramp. This means that his back wheel lands marginally before his front wheel - a style of riding off a ramp or drop-off that lessens the chance of what is called an 'endo' occurring. An example will be provided below, but in brief 'endo' is short for 'end-over-end' and can occur when a rider's front wheel drops first, but the back wheel has sufficient momentum and elevation to carry it over the front wheel, catapulting the rider over the bars and into the dirt. 'Endos' can result in serious injury.

Clearly, in this case Q25's riding does not result in an endo, nevertheless, in other circumstances it could constitute a dangerous style of riding, something much less likely with G6's back-wheel first landing. From considerations such as those above, the reader may now have a better feel for the suggestion that 'gender difference' is a key issue that many see in the video. The issue can be put fairly starkly: given that there are visible differences in the gendered riding on display, is the video trying to encourage a reading that women cannot mountain bike like men? Do the female riders on view not actually have the 'skills to pay the bills'? All three can clearly ride a mountain bike, but in comparison to the riding of the young males that have gone before, they seem to ride in a much more limited and constrained fashion. They ride off the lowest level of the ramp, and either avoid the jumps, or if they ride them, do so very cautiously not using the jump to get airborne. As noted above, this is the reason why a very skilled female mountain biker, upon viewing the video, does not even formulate the difference but immediately reacts by suggesting that with the increased opportunity for training in skills that now exists, contemporary female mountain bikers can now ride like the young male mountain bikers who dominate the video.

To make it clear, I have no interest as both a male academic and a male mountain biker in suggesting women cannot ride mountain bikes like men. My interest is in opening up the complexity of skill on display, understanding what we see as an organisational thing, and bringing in the undoubted importance of the material dimension to this understanding. This is pursued in the next section by first considering an existing study of urban cycling that has a brief 
discussion relevant to this issue and how it might be conceptualised. Then another mountain biking video is briefly considered to highlight something that we do not see in the skills video - what happens when things go wrong - as I suggest this is a key part of the organisational thing under examination.

SITUATED DIFFERENCE AND MULTIPLE SKILLS

Latham and Wood (2015) explore the interactional spaces of urban cycling in London. They provide a rich description of the variety of cycling commutes, nevertheless showing how all cyclists' commuting practices occur within 'existing infrastructural configurations' where 'the central figures in this movement are quite clearly motor vehicles' $(2015,302)$. They are interested in the fact that while cycling is increasing in London, there is an 'infrastructural settlement' that has considerable 'obduracy'. In short, the current settlement works best for motorised road users and people on foot, but leaves cyclists in an indeterminate position. Empirically, they detail the diverse range of approaches to negotiating movement through the city on bikes, given the more risky position cyclists find themselves in.

Amongst this detail there is one example more pertinent to the case study here. They describe Gail, a female accountant, commuting on a fold-up Brompton bike. Gail's riding is amongst other traffic, including other cyclists, and in relation particularly to the latter, her riding is noticeably slower and less risky. She does not break rules as to proper positioning on the road, being content to cycle at a slow pace, and she does not connect up with other faster riders who attempt to ride as a bloc thus forcing car drivers to slow and give them space on the road. Latham and Wood's conceptualisation of her riding is an important one, worth a lengthy quote:

if London's infrastructural settlement affords certain styles of hightempo cycling, this does not mean that those who cycle slowly are necessarily lacking in skill... With Gail it is not that she lacks the skills to join the other cyclists (although her age, physical capacities, and choice of bike work against that); it is that Gail has over her many years of commuting developed a very different style (and speed) of cycling. This is a style that is actually very effective in keeping her in motion. And it is a style that rests on a rather different set of skills than that used by faster riders. Gail is notably skillful at finding her own rhythm in the face of the dominant rhythm of the traffic around her. This is quite an achievement. But it is one unsupported by other cyclists. $(2015,311-312)$ 
Interestingly, Gail is female, and the cyclists that ride more riskily, and faster, past her are male. However, Latham and Wood do not use this to develop an argument about possibly gendered styles of riding. Their interest instead is in how all styles of riding in this situation have to be understood within the situated logics of the 'infrastructural settlement', and given this, it is not necessary to map faster/slower directly onto skilled/less skilled, nor onto male/female. Thus, the skill in Gail's riding partly lies in knowing what rhythm works for her and not being enticed into riding at a pace that does not suit her.

In my view, this empirically based insight has important implications for our case under consideration, specifically for how the riding of the three female riders in the skills area is interpreted. Exactly like the male riders who pass Gail in the London traffic, the three female riders have been seen riding the same structures as the young males, making the difference in riding styles immediately observable. It could also be inferred that, just like the rest of the audience, they have been watching the faster and more risky riding of these males, however, akin to Gail in the urban commute, they are not enticed into attempting to reproduce the young male style of riding. The point is this: parallel to Gail's urban cycling, the women mountain bikers are riding at their own rhythm and pace, and this is an achievement and a skill in itself.

As to it being 'unsupported by other cyclists', this is something that requires further discussion, particularly taking into account the differences between commuting cycling in London and mountain biking in a skills area. Urban cycling, as a mode of commuting, is oriented to the function of getting from A to B. As Latham and Wood detail, this is an environment where cyclists are in an exposed and risky position: unlike pedestrians, they do not have their own space, but must share the road with larger vehicles that can seriously injure them in any collision. The speed and positioning of any cyclist is thus a skillful response to this situated constraint, given the function of commuting.

In contrast, the mountain bikers riding in the skills area are not commuting from point $\mathrm{A}$ to $\mathrm{B}$. Their riding is pleasure oriented, where the riding within the skills area can be pleasurable in itself, but can also provide improvements and lessons' that can be taken away from the skills area and put into effect in riding on any other mountain bike track. At risk of over-generalisation, it can be said that the embodied and mobile experience of 'speed and flow' are central to the pleasures that mountain biking can produce. At the same time, speed and flow are undergirded by a third factor: risk. And, mountain biking risk differs significantly from the risk in the urban commuting case: the risk in the latter predominantly comes from other vehicles, which are not present 
in the mountain biking park, so the skills area is a space more purified for cycling than urban streets (on the normalisation of risk in road cycling, see Albert 1999). Such purification does not lessen risk, it just means it comes from a different source. Mountain bikers do not suffer from being hit by cars, but the practice itself has its own endogenous danger: when travelling at speed on rough tracks with obstacles on and off the track, crashes are common and often result in relatively severe injury. What I want to suggest is that the speed, pleasure and risk coalesce into an organisational thing intimately known and taken for granted by mountain bikers. The challenge is to somehow glimpse this in action, to somehow put it on paper. The best way to do this here is by considering a second mountain biking video where something goes wrong, when risk is made tangible in a crash. There is nothing like this in the skills area video, nonetheless, it is an ever-present possibility, and as shown in Figure 5 , one that can happen remarkably easily.

The figure shows screensnaps from a video of a group of five mountain bikers riding a structure known as a 'gap jump'. In essence, this is like the humps of Jumps 1 and 2 of the skills area, except that the middle of the hump is not there, meaning that once committed to entering the first side a rider must get airborne to move to the landing side of the jump. Needless to say, skill particularly control of speed and bike position - is required to do so. Frame one is twenty-nine seconds into the video, and prior to this the rider with the helmet-mounted camera (R1) has successfully ridden over the gap jump and has returned to the side of the jump with his camera still recording. In frame one we see a second rider about to land after clearing the jump, with a third rider $\left(\mathrm{R}_{3}\right)$ approaching. In frames two and three we see that even though $\mathrm{R}_{3}$ approaches the gap jump he pulls out of it, turning to the side, braking and rolling through at ground level. At frame three, precisely as he has slowed and is approaching R1 he says, 'Oh no', to which R1 replies, 'Go through - it's quite - you had enough speed there'; R3 says, 'Eyy', and R1 replies, 'You had enough speed. So, in just these few seconds, after R1 and $\mathrm{R}_{2}$ have successfully cleared the gap jump, $R_{3}$ and $R_{1}$ jointly make accountable $R_{3}$ 's failure to ride the gap jump. R3's 'oh no' is made both to himself and to the watching and filming R1, and indicates that he had wanted to take on the gap jump, but is disappointed at not having done so. Ri's 'go through' is to say that he should ride past him where he is in a stationary position filming subsequent riders. The next utterance - 'it's quite' - is cut off, but it could be inferred he was saying, 'it's quite difficult'; either way the more notable thing that R1 says is the repetition of, 'you had enough speed there. This is his observer's evaluation of R3's riding which is perhaps encouraged by the latter's own expressed disappointment 'oh no' - at not having jumped the gap. Jointly, their actions show that jumping 

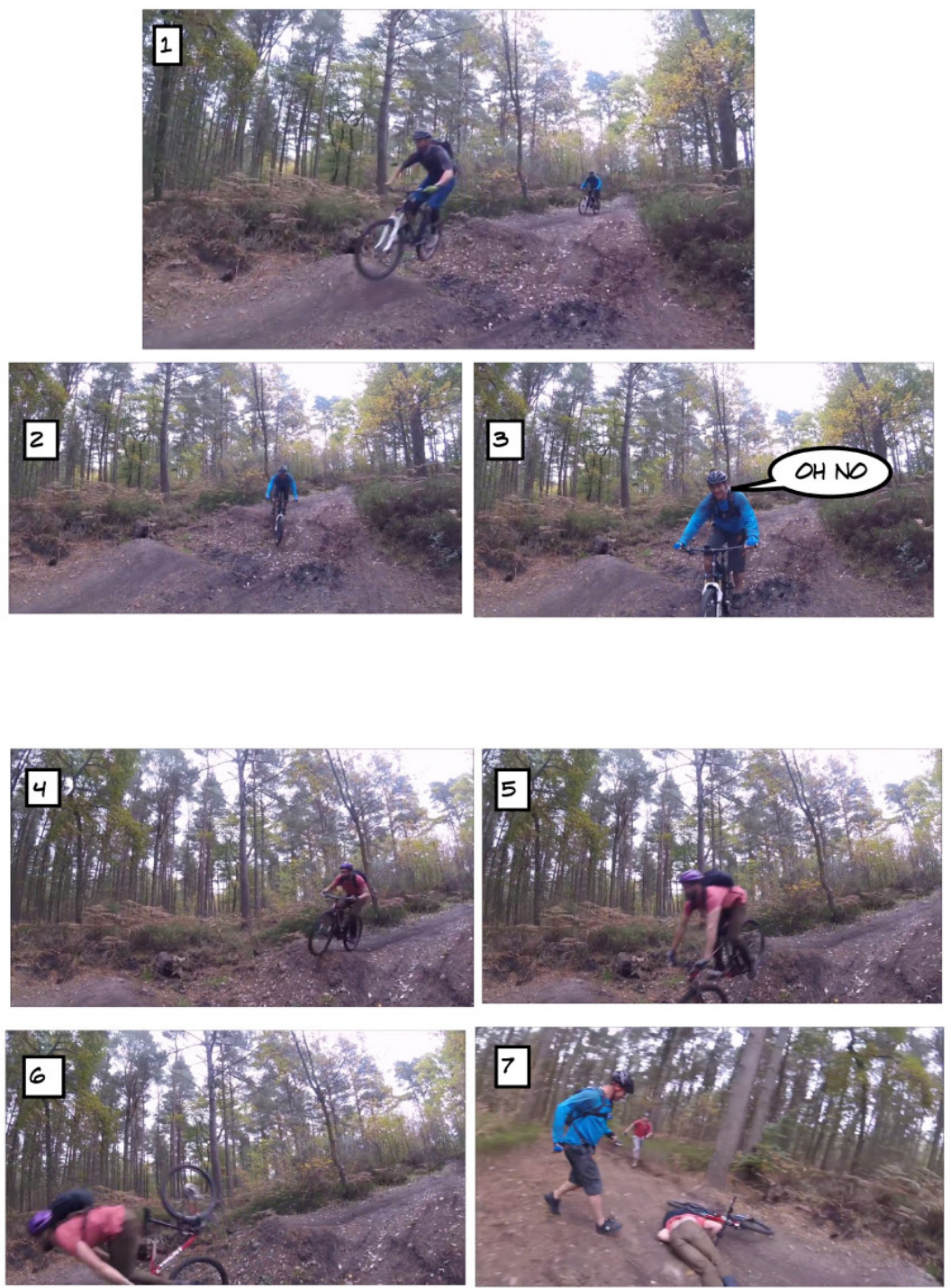

Figure 5

the gap is normatively organised as the preferred course of action, thus setting up for $\mathrm{R}_{3}$ what we could call an 'instructed challenge': next time out riding the track, $R_{3}$ should take on the gap jump. If this is accepted, what happens next is very significant. 
One other rider ( $\mathrm{R}_{4}$, not shown) successfully clears the gap jump prior to the appearance of $\mathrm{R}_{5}$ in frame four. In that frame we see $\mathrm{R}_{5}$ cresting the first side of the jump, but already something is wrong with his technique: he has not managed to project his bike sufficiently upwards, as indicated by the horizontal plane his front wheel occupies (see the comments above about front wheel position). In frame five we see he is in the air but is falling well short of the landing side of the jump, and in frame six we see the disastrous consequences of this as he begins the catapult of an 'endo'. His bike does not clear the landing side of the jump, instead his front wheel hits early, thus catapulting him headfirst over his handlebars. In frame seven, as $\mathrm{R}_{3}$ rushes to his aid, he is already unconscious from the impact of hitting the ground. ${ }^{7}$ We can only wonder if having witnessed R5's horrible crash, and now as he rushes to attend to him, $\mathrm{R}_{3}$ might be thankful for his own decision to pull out of the jump - he may have done a sensible thing in being more cautionary.

There are many other mountain biking videos available that show similar crashes, however, this particular one is useful for the way it shows a group of riders rendering their riding of a gap jump accountable, and for the very ordinary manner in which the accident unfolds. None of them appear to be doing anything unusual; certainly, $\mathrm{R}_{5}$ simply rides along, attempts the jump, and then fails spectacularly in the course of only a few seconds. Bringing this back to the skills video, the first point that needs emphasising is that at any moment similar accidents could have happened in the riding that opened the skills area. No crashes are shown, but what I want to argue is that the mountain bikers displaying their skills fully know that crashes are possible at any moment, and on any part of the features of the skills area. This members' knowledge forms an essential background to the riding that they display.

So, to return to the specifics of the three women's riding, we can push even further away the interpretation that they are less skilled than the young males. Part of N22's skill lies in knowing that if she rides onto Jump 1, the speed she is travelling at will make her airborne, and so she avoids Jump 1. In contrast, Q25 and R26 ride at a slower pace up Jump 1, and this may well be intentional for they know it will not make them airborne; that too is a skill. Just like Gail in her urban commute, they are out there riding the skills area, and they do ride up the jump, just at a different pace. It is not unreasonable to infer that they are in control of the pace they ride at, and in light of the risk of crashing at any time, with the sometimes horrific consequences (as above), this is a skill that cannot be underestimated. 
Finally, there is the question of whether, despite this argument about the women's skill, their style of riding faces an equivalent of the male urban commuting cyclists' reaction, that is, being unsupported by other cyclists. This is a difficult question to answer, however, there is one final piece of the jigsaw that we can view to close on. Consider Figure 6.

This screensnap is from a small interlude in the riding action, and shows a young male carrying a bike that has a broken derrailleur hanger. We do not see what caused this breakage, but it would have required a reasonably high impact. More importantly, attentive viewers will be able to recognise the young male as G6 (see Figure 2): one of the youngest male mountain bikers who in riding Jump 1 gets the biggest air off the jump. To then see him later in the video carrying his bike with a broken derailleur is an obvious, if silent lesson: the skilled riders who make the more showy maneuvers also face an elevated risk of crashing. This 'lesson' is there to be taken even if we do not see the cause of the breakage. In my view, this takes us away from the interpretation that the more cautious riding of the women is 'unsupported' by the male riders; instead, it is a visual reminder of just how sensibly skilled their style of riding is. The brief shot of the breakage was put there by the video's maker, and its inclusion adds something significant to the collective picture.

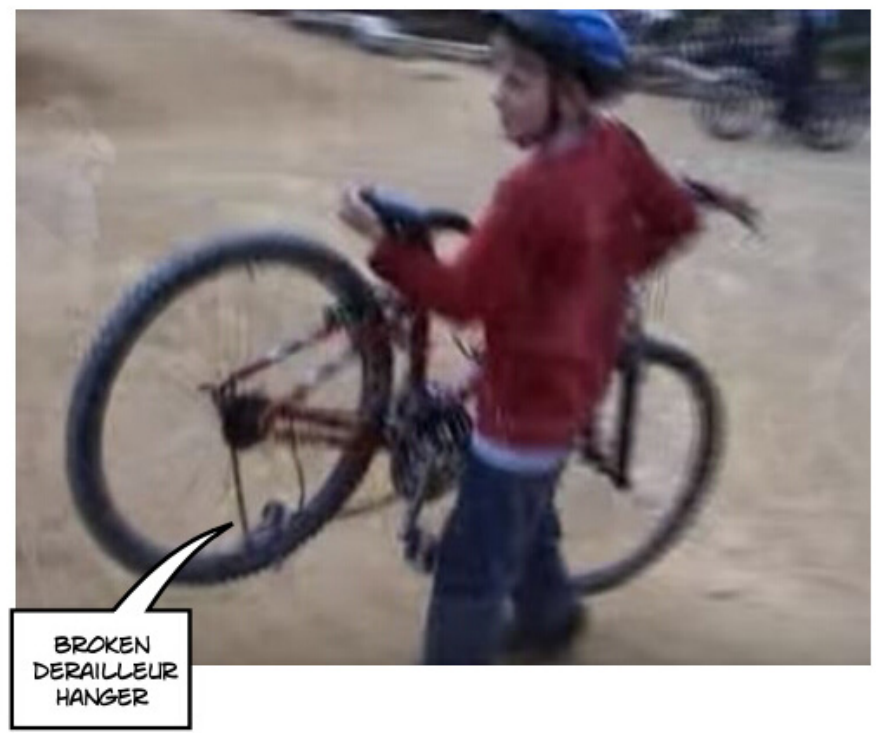

Figure 6 
The upshot of all of the above can be briefly stated: given the details that we see, in the context of the organisational thing of opening the skills area, it is mistaken to jump to the interpretation that the video portrays women mountain bikers 'riding like a girl'. All of the riding is skillful in various ways, and the song that plays during this riding action captures this precisely: skills to pay the bills. That is, there is no singular bill that needs to be paid by a singular skill.

\section{CONCLUSION}

As noted in the introduction, I was not present on the day of the opening of the Makara Peak skills area. Ethnographic fieldwork on that day, perhaps including some video capture, would have been useful. At the same time, it may have produced an excess of data. As Garfinkel and Wieder put it, any study of interactional events 'being done by and available to the parties first time through, are for both lay and professional analysts, at one and the same time easily recognised and intractably difficult to describe (1992, 183, original emphasis). Even a thirty minute video capture of the skills area opening would face this descriptive problem, compounded by the constraints of publication in a word-dominated medium. Consequently, even though the video analysed here is highly framed and edited, making it a selective record, at the same time its focus is useful, providing more than enough for close analysis: thirty-two runs by nineteen mountain bikers does constitute a decent look at mountain biking practice. In focusing on the question of 'gender difference' I have taken a selective approach to this description, but I hope to have provided the reader with sufficient grounds to explain the choice of focus and analytic process.

In a discussion of the difference between 'naturally occurring data' and 'naturally organized ordinary activities', Lynch makes an important point consistent with Garfinkel and Wieder above. That is, 'research is not a matter of observing and analyzing previously unknown orders of things: rather, it is a matter of reviewing, articulating, and hopefully gaining fresh insight into, what we (and/ or those we study) already know' (Lynch 2002, 535). A good way to elaborate the relevance of this is to bring Scarlett Hagen back into the mix. In the introduction I used a comment by her to show, in effect, that it was not just my interpretation that the video showed a 'gender difference', as other people saw this too. Then I went on to show that the difference in riding observable in the video should not be considered as a deficiency. The women riders, while slower and more cautious, were riding in a skillful manner. This is because their riding has to be placed in the context of the common knowledge of risk in mountain biking. On this, consider some extra information on Hagen from a newspaper article: 
Former junior world champion mountain biker Scarlett Hagen is now running a bike coaching business ... Scarlett Hagen had surgery last year to remove 27 pieces of metal holding her body together just part of the cost of being a top downhill mountain biker. They were in both elbows, a shoulder, a leg and an ankle ... "I think I broke 17 bones", she laughs. "It's part of it". (Jamieson 2015)

Note that in this, Hagen is described as a 'top downhill mountain biker', and the word 'female' does not appear between 'downhill' and 'mountain'. Of course, we can read from 'her' and 'Scarlett' that she is indeed female, but is this a required reading? Or, as ethnomethodologists would put it, is gender here an 'occasioned' phenomenon (Garfinkel and Wieder, 1992)?

In an important recent article Hirschauer (2017) has argued that increasingly 'gender indifference' is a key topic for sociological inquiry. As he puts it:

The theorem of 'doing gender' ... projected the high relevance of gender for gender studies onto the object of investigation, despite gender difference being only one kind of classification for members of society ... Moreover, the conditions under which the mere background relevance of gender actually becomes a focus and a topic of interactions were not specified. Put differently, an important theoretical implication of 'doing gender' was simply omitted, namely that of 'undoing gender' ... The fundamental notion of a practical doing of affiliations and distinctions implies that people may also refrain from doing them. To the extent that they practically perform meaningful distinctions, they may interrupt, abstain from or discontinue this process of performance, and they may deactivate memberships within specific situations or fields. (2017, fn 8 , original emphasis)

This argument cannot be pressed too hard given the limitations of the data analysed here. Nonetheless, in emphasising how competent mountain bikers might view the video in light of their members' knowledge of the centrality of risk, there is a compatibility with Hirschauer's argument. We simply cannot assume that 'gender' is the central operative category to be enacted when we see three woman mountain bikers 'overshadowed' by male riders performing showy stunts.

This does not mean, either, that 'gender' totally disappears. But, it is to say that surely we have to try to understand the video as the production of a community of practice, and only then ask when it is that the community members 
treat gender as relevant to their situated concerns. Within this community, loosely knit as it may be, when entering the skills area, their mountain biker's eyes are drawn not to the flat ground, but to the high ground above the threelevel ramp, which they 'naturally' see as a launching slope providing high momentum for a run downhill, off one of the levels of the ramp, and then onto one of the jumps, where it is their control of speed and bike position which will determine whether they get airborne in the process. The slope is not seen as something with which to practice riding uphill, but as a gravity fed multiplechoice pathway: the materials for producing excitement. The builders of the skills area, now long gone, knew that when they put this organisational thing in place. But the objects and layout of the skills area are only a skeleton; in the riders' skillful control of speed and bike direction, they put the flesh on the skeleton of the skills area. And in that process, multiple types of mountain biking competence are available for viewing. In my view, the video of the skills area opening is a record (and celebration) of that, and not some attempt to channel interpretation towards gender-based limitation.

\section{ACKNOWLEDGEMENTS}

I would like to thank Sanna Fourt-Wells and Max Baddeley for encouragement and feedback on this work as it progressed. Also thanks to the anonymous reviewers for comments on a previous version of the article.

\section{NOTES}

1 Mike Lloyd is a sociologist at Victoria University of Wellington. His recent research has involved working with video data, including studies of cycle rage $\mathrm{CHu}$ man Studies, Mobilities), and driver-cyclist interaction in the Island Bay Cycleway, Wellington (Applied Mobilities).

2 The video is still posted on Youtube (Makara Peak Skills Area Grand Opening 2007). Ideally, readers would view the video before reading any further, perhaps also returning for repeated views in relation to the analysis section. Colour versions of the figures herein can be found in the online presentation of this article.

3 Whereas the video is now ten years old, there are good reasons to believe that the quantitative gender imbalance it shows has not changed significantly. For example, at a public meeting in 2016 to discuss future developments in the Makara Peak Mountain Bike Park, there were only three women present in an audience of at least 30. 
4 See Ivarsson and Greiffenhagen (2015) who use the same device in their analysis of the organisation of turn-taking in pool skate sessions.

5 These constitute two thirds of the runs shown in the video.

6 Owing to space constraints, I have been using some mountain biking jargon without explanation. Interested readers could peruse any mountain biking magazine or website to quickly find the meaning of the terms.

7 R5 remains unconscious for several minutes, an ambulance is called, and ultimately he recovers from the crash. The full video is available on Youtube (https:// www.youtube.com/watch?v=ek4yFrMvjMo).

\section{REFERENCES}

Akrich, M. 1992. 'The De-scription of Technical Objects'. In Shaping Technology Building Society, edited by W. Bijker and J. Law, 205-224. Cambridge: MIT Press.

Albert, E. 1999. 'Dealing with Danger: The Normalization of Risk in Cycling'. International Review for the Sociology of Sport 34 (2):157-171.

Dant, T. 2004. 'The Driver-Car'. Theory, Culture and Society 21 (4/5): 61-79.

Gafinkel, H., and D.L. Wieder. 1992. 'Two Incommensurable, Asymmetrically Alternate Technologies of Social Analysis'. In Text in Context: Contributions to Ethnomethodology, edited by G. Watson and R.M. Seiler, 175-206. Newbury Park: Sage.

Goodwin, C. 1994. 'Professional Vision'. American Anthropologist 96 (3): 606-655.

Hirschauer, S. 2017. 'Gender (In)difference in Gender (Un)equal couples'. Human Studies early online version, 13 June.

Huybers-Withers, S.M., and Livingston, L.A. 2010. 'Mountain Biking is for Men: Consumption Practices and Identity Portrayed by a Niche Magazine'. Sport in Society 13 (7/8):1204-1222.

Ivarsson, J., and C. Greiffenhagen. 2015. 'The Organization of Turn-taking in Pool Skate Sessions'. Research on Language and Social Interaction 48 (4):406-429. 
Jamieson, D. 2015. 'Former Top Mountainbiker Scarlett Hagen Turns Her Passion into a Profession, The Southland Times, March 31. Accessed 15 July 2016 from http://www.stuff.co.nz/southland-times/67560079/former-top-mountainbiker-scarlett-hagen-turns-her-passion-into-a-profession

Jarzabkowski, P., and T. Pinch. 2013. 'Sociomateriality is 'The New Black': Accomplishing Repurposing, Reinscripting and Repairing in Context'. M@n@gement 16 (5): 579-592.

Jutel, A. 2009. 'Running Like a Girl: Women's Running Books and the Paradox of Tradition'. The Journal of Popular Culture 42 (6):1004-1022.

Kennett, J., Kennett, S., and P. Kennett, 2014. Classic New Zealand Mountain Bike Rides - North and South, gth Edition. Wellington: The Kennett Brothers.

Kotarba, J., and M. Held, 2006. 'Professional Female Football Players: Tackling Like a Girl?' In Body/Embodiment: Symbolic Interaction and the Sociology of the Body, edited by D. Waskul and P. Vannini, 153-170. Aldershot: Ashgate.

Latham, A., and P.R.H. Wood, 2015. 'Inhabiting Infrastructure: Exploring the Interactional Spaces of Urban Cycling. Environment and Planning A 47:300-319.

Latour, B. 1992. 'Where are the Missing Masses? The Sociology of a Few Mundane Artifacts'. In Shaping Technology/Building Society, edited by W. Bijker and J. Law, 225-258. Cambridge: MIT Press.

Latour, B. 1994. 'On Technological Mediation: Philosophy, Sociology, Genealogy'. Common Knowledge 3:29-64.

Lynch, M. 2002. 'From Naturally Occurring Data to Naturally Organized Ordinary Activities: Comment on Speer. Discourse Studies 4 (4):531-537.

Makara Peak Skills Area Grand Opening - 2007. (video). Accessed 21 March 2016 from https://www.youtube.com/watch?v=2ysxf7w-jbA

Maynard, D. 2012. 'An Intellectual Remembrance of Harold Garfinkel'. Human Studies 35:209-221.

Nevile, M., P. Haddington, T. Heinemnann, and M. Rauniomaa. 2014. Interacting With Objects: Language, Materiality and Social Activity. Amsterdam: John Benjamins. 
Article $\cdot$ Lloyd

Rinehart, R.E., and S. Sydnor. 2003. To the Extreme: Alternative Sports, Inside and Out. Albany: State University of New York Press.

Sayes, E. 2014. 'Actor-Network Theory and Methodology: Just What Does it Mean to Say that Nonhumans Have Agency?' Social Studies of Science 44(1):134149.

Sudnow, D. 1993. Ways of the Hand: The Organization of Improvised Conduct. Cambridge: MIT Press.

Tuma, R. 2012. 'The (Re)construction of Human Conduct: "Vernacular Video Analysis"'. Qualitative Sociology Review 8 (2):152-163.

Young, I. 1990. Throwing Like a Girl. Bloomington: Indiana University Press. 